\title{
Informing the future of Australian mining through climate change scenarios
}

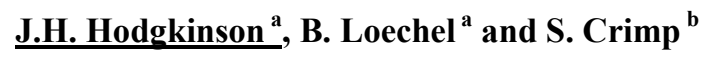 \\ ${ }^{a}$ Climate Adaptation Flagship, CSIRO, CESRE, Technology Court, Pullenvale, Qld 4069 \\ ${ }^{b}$ Climate Adaptation Flagship, CSIRO, CMIS, Black Mountain, ACT 2601 \\ email: jane.hodgkinson@csiro.au
}

\begin{abstract}
Mining value chains are vulnerable to a changing climate mainly due to the likelihood of increases in the incidence of extreme weather events. As such events will potentially become more frequent and more intense, the associated impacts such as infrastructure damage, production delays and downtime may damage mine profitability, staff safety, company reputation, regional 'liveability' and government revenues. Mining adaptation strategies to better deal with such impacts can be developed but the options available cannot simply be applied 'across the board' at all mines and in all situations.

Various types of mining in Australia occur across 11 main geographic areas, each with its own processes and needs, its own climate signature and its own extreme-event profile. To provide some context for the likely changes in future climate, CSIRO has developed mining region-specific scenarios in association with the OzClim Climate Change Scenario Generator. OzClim generates climate change scenarios using pattern scaling where the change at a particular grid point is normalised by the mean global warming produced by the model for a doubled $\mathrm{CO}_{2}$ concentration in the atmosphere. The patterns of change are produced for each of the 23 global climate models and for the purposes of the Australian mining regions, we have expressed changes consistent with an historical baseline in order to make the projection information as contextually relevant as possible.
\end{abstract}

To bridge the gap between scenarios and users, CSIRO facilitated workshop events in mining regions. Representatives of a cross-section of the mining chain (including energy, mining, transport, research, water and community stakeholders) were invited to attend, some of whom were first interviewed by facilitators to gain an insight into their operations, understandings, and needs with regard to the workshop. The attendees were presented with future regional climate scenarios, additional information from other studies and climate location analogues helping to further 'set the scene' for the future and helping to facilitate discussion around potential impacts and adaptation needs. Discussions at the workshops provided the means for the scenarios to be placed in their local context, whilst hearing how others in the chain may be directly and indirectly impacted and how they may adapt.

Mines and their related infrastructure are frequently long-term investments for all concerned. Therefore, future climate scenarios are valuable for mining value chains and the decision-makers to envisage and plan the future, including adaptation at established sites, alternative processes at new sites and contingency plans that accommodate new levels of variability. Utilising workshops to link future climate scenarios to the value chain and its operational components assisted the end-users to visualise, conceptualise and engage with adaptation decision-making scenarios. The event also brought together participants from different parts of the mining chain who were able to share knowledge and discuss needs that may in the future aid adaptation and avoid maladaptation.

Keywords: $\quad$ Mining, climate change, scenarios, workshop 


\section{INTRODUCTION}

As a resource extraction industry exposed to the natural environment regardless of season or weather, the Australian mining chain faces many climate-associated challenges (Hodgkinson et al. 2011). Coping with weather events is part of the mining 'way-of-life'; expecting them is based on historical data and plans to deal with them are typically based on past experience. Adaptation to future climate change in this industry has some barriers, one of which is the inability to recognise the potential for increased future vulnerability (Loechel et al. 2013a; Nelson et al. 2010). Reasons for this may include conflicting or confusing evidence of change, and modelling or data products that are typically inaccessible or hard to interpret (Adger et al. 2005; Hall et al. 2007). Here we discuss one way in which the use of future climate scenarios has been explored in the mining industry and how it is bridging the gap for those who understand that historical data may not be the best planning tool for the future.

\section{BACKGROUND}

The mining industry is an important economic sector in Australia, contributing around $8 \%$ of GDP, producing over half the nation's exports by value, and providing significant employment (ABS 2012a,b). Mining occurs in 11 mining regions around Australia (Figure 1), each experiencing distinctive climate types and extremes and each, therefore, with its own challenges. The mining chain is frequently impacted by extreme events such as floods, drought or cyclones and since the industry cannot simply relocate, it is accepted as the operating 'norm' (Hodgkinson et al. 2011). Whilst an industry-wide economic assesment of climate-impact is not currently available, evidence of costly impacts is available in portions of the sector. The 2010-11 flooding of the Queensland coalfields for example, caused widespread closure for several months. The cascading effects forced global coal prices up as clients looked elsewhere for supplies, cost mining companies billions of dollars in remediation and lost revenue, impacted on Australia's economy by AU $\$ 0.5 \mathrm{bn}$ per month of closure and cost the coal sector an estimated AU $\$ 5$ bn and AU\$9 bn (Loechel et al. 2013a, QRC 2011). Different parts of the chain typically cope with impacts through planned and reactive processes informed by historical data and previous experiences. Mines usually incorporate 'downtime' into their production plans, providing time during or after an extreme event so that production figures are not reduced compared to their forecast figures. As a result of climate change and as extremes intensify, there is the potential for downtime to increase along with greater hazards and new challenges or opportunities. Adaptation to new or expected patterns to reduce vulnerability will allow companies to take advantage of changes. An industry-wide survey of Australian mining companies (Loechel et al. 2013a) identified that few vulnerability or adaptation projects have yet been undertaken. In many cases, this appeared due to a lack of useful data or inability to interpret the existing data in a way that aided assessment of future climate scenarios. The ability to improve understanding of climate projection data, through facilitated workshop engagement with projections data, has been an valuable step towards the industry's identification of operational vulnerability and assessment of their capacity and requirements to adapt. 


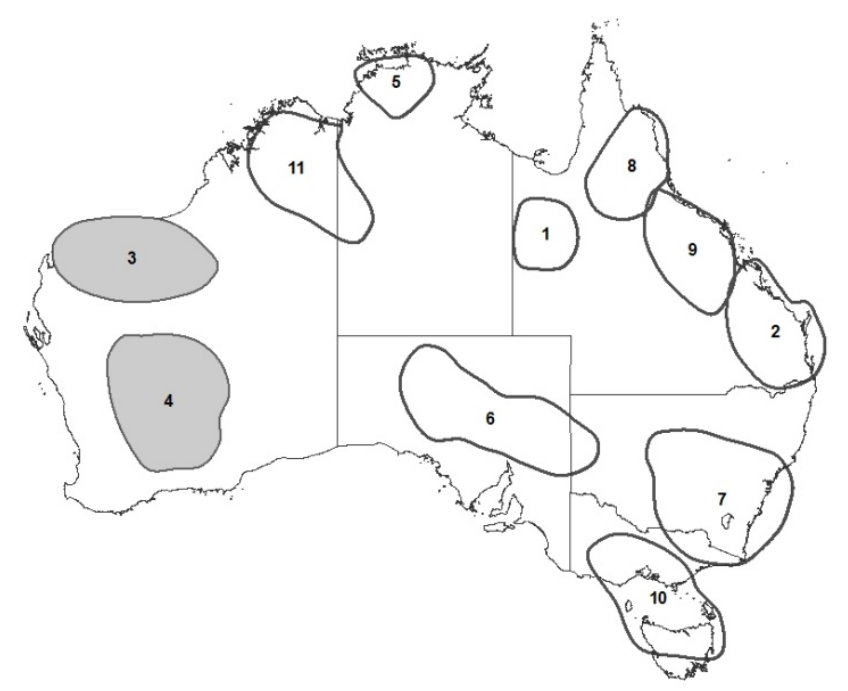

Figure 1 Map of Australia showing 11 distinct mining regions with workshop locations, regions 3 (Pilbara) and 4 (WA Goldfields) highlighted.

\section{OzClim CLIMATE SCENARIOS}

OzClim is a user-friendly, educational, visualisation web tool that provides Australian climate scenario outputs for exploring sectoral vulnerability to climate change (Fig 2). It allows a wide range of future climate change projections to be assessed as it contains monthly, seasonal and annual climate change factors from 23 on a $65 \mathrm{~km}$ grid across Australia for five yearly intervals for the $21^{\text {st }}$ century on a monthly, seasonal and annual basis (CSIRO \& BOM, 2007). The 23 global climate models run by research centres including CSIRO, are archived at the Program for Climate Model Diagnosis and Intercomparison (PCMDI) and underpin research that forms part of the Intergovernmental Panel on Climate Change (IPCC) Fourth Assessment Report (2007). Users can download data by visiting the site http://www.csiro.au/ozclim/home.do.

For the purposes of this study projections from four climate models were selected. This selection was based upon skill criteria derived from a number of studies. These included:

- $\quad$ Number of rainfall criteria failed (Smith and Chandler, 2010)

- $\quad$ Demerit points based on criteria for rainfall, temperature and Mean Sea Level Pressure (MSLP)

(Suppiah et al., 2007)

- $\quad$ M-statistic representing goodness of fit at simulating rainfall, temperature and MSLP over Australia (Watterson, 2008)

- $\quad$ Satisfied criteria for daily rainfall over Australia (Perkins et al., 2007)

- $\quad$ Satisfied ENSO criteria (Min et al., 2005; van Oldenborough et al., 2005)

- $\quad$ Satisfied criteria for SST variability (Overland and Wang, 2007)

- $\quad$ Satisfied criteria for daily rainfall over MDB region (Maximo et al., et al., 2008)

- $\quad$ Satisfied criteria for MSLP over MDB region (Charles et al., 2007)

- $\quad$ Below median errors for 14 variables (Reichler and Kim, 2008).

- $\quad$ Below median rankings for 4 variables over Antarctica and the globe (Connolley et al., 2007)

While this method of assessment is somewhat subjective, it is apparent that some models consistently underperform. In particular, models with a failure rate greater than $65 \%$ were deemed of little or no use in the development of future projections. On the other hand, some models consistently provided skill full projections and, while there is no agreed method for defining the "best" models, it was clear that eight models are more likely to produce credible projections. In particular, these eight include the six models 
which have credible representations of ENSO - an important component of Australia's climate variability. The four models used in this study were selected from the set of eight "best" performing models to provide a range of possible climate futures. The models included the National Centre for Atmospheric Research Model (NCAR), the Max Planck Institute for Meteorology Model (ECHAM), the Geophysical Fluid Dynamics Laboratory Model (GFDL) and the Hadley Centre Global Environmental Model (HADGEM).

To produce the future projections, the regional pattern of change in both temperature and rainfall was normalised by the extent of warming produced by each model for a doubling of $\mathrm{CO}_{2}$. The normalised patterns of change can then be scaled according to a particular emission scenario. In figure 2 the normalised pattern of change is scaled by $3.01^{\circ} \mathrm{C}$ as this value represents the warming from the SRES A1FI scenario for 2060 . For the purposes of this study the normalised patterns from the four different GCM's were scaled by a 2030 global warming value consistent with that produced by the SRES A1FI emission scenario.

The selction of relevant future scenarios represents the first step in data provision. For the information to have real value and allow effective utilisation by decision-makers it is crucial to provide the information in a context that is relevant. This can include relating the climatic change to changes in other biophysical, economic or social drivers. The information can be effectively leveraged through a workshop delivery mechanism. In this process, projections data can be clearly explained and can be supported with other climate information, and participants have the opportunity to ask questions, consider and discuss implications, and interact with practitioners from other areas. The scenarios also provide clarity for users where uncertainty from multiple-models may lead to a mistrust of data that in turn, may lead to non- or mal-adaptation.

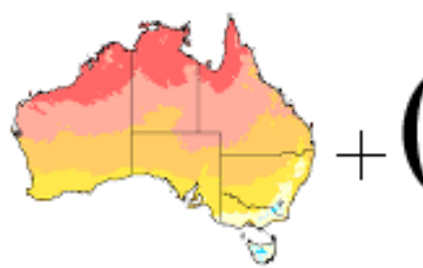

Baseline Climatology

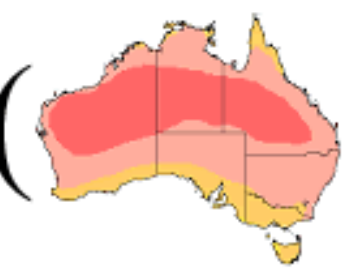

Regional pattern from GCM
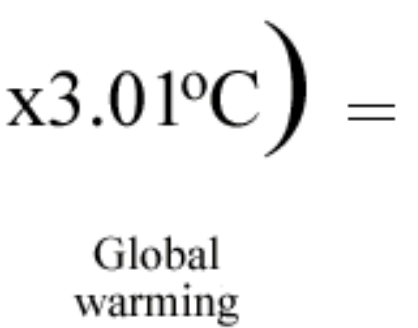

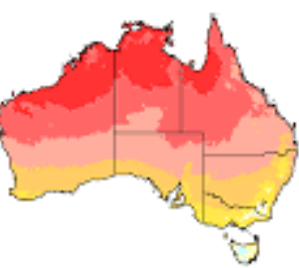

Result 2060

Figure 2 An example climate scenario generation for annual temperature in 2060. The regional pattern from the GCM is multiplied by the global warming and added to the observed baseline climatology. In this example, the GCM is CSIRO Mk3, the emission scenario is SRES A1F1, and the rate of global warming is high (source https://wiki.csiro.au/confluence/display/ozclim/Science\#Science-FutureCC)

\section{SCENARIO DELIVERY TO MINING}

CSIRO conducted workshops with a spectrum of mining value-chain representatives (such as mining, energy, water, transport, research and community stakeholders) where region-specific climate scenarios for 2030 and 2070 were presented for discussion (see Tables 1 and 2). Prior to the workshops taking place, attendees were invited to be interviewed by facilitators, and this provided valuable information on their operations and understandings of climate change and its implications, allowing the workshop to be planned accordingly. The workshops involved presentations of climate projections data, followed by large and small group discussion of climate scenarios, and small group exercises focussing on identifying vulnerabilities and adaptation options.

In the Pilbara region for example (Table 1), the projections data, together with information on increasing intensity of cyclones and uncertainty of ocean warming potential, was used to inform consideration of both 'warmer and wetter' and 'warmer and drier' climate future scenarios (Loechel et al. 2011). These scenarios indicated the region will be more demanding for communities and industry, with more extreme heat, intensified cyclones and increased water scarcity.

In the Goldfields region of WA, two workshops were presented to mining value-chain representatives, at which a generally hotter and drier future scenario, but with drier winters and wetter summers, was put forward (Loechel et al. 2010, Loechel et al. 2013b). The second workshop was initiated to further develop understanding for and of the region, to continue cross-sectoral discussion on future development of the region under changing climatic conditions (Loechel et al. 2013b). The scenario provided at the workshops was 
supported by historical trend data over the past 50-60 years (Bureau of Meteorology 2013) and climate change information from the Indian Ocean Climate Initiative (IOCI 2012) showing severe winter drying in south-west Western Australia together with southward expansion of tropical influences and ex-cyclones. For the mining chain in the Goldfields region this was seen as presenting a mix of threats and opportunities, structured by the seasonal shift in rainfall from winter to summer. For example, workshop participants revealed that even small falls of rain can render unsealed mining haul roads impassable, so drier winters may be beneficial in improving production at that time of year but these gains could be offset by more disruption to production from rain events in summer (Loechel et al. 2013b). Participants were also presented with analogies between the future scenarios and the current climate in an existing area or town, to further illustrate how the future climate may be, providing participants with an additional tool for discussion and understanding.

Table 1. Projected change scenarios for temperature and rainfall in Region 3 according to four of the best performing climate models available (derived from OzClim data and Kokic et al. 2011) as presented to workshop participants in the Pilbara, WA (Source Loechel et al. 2011)

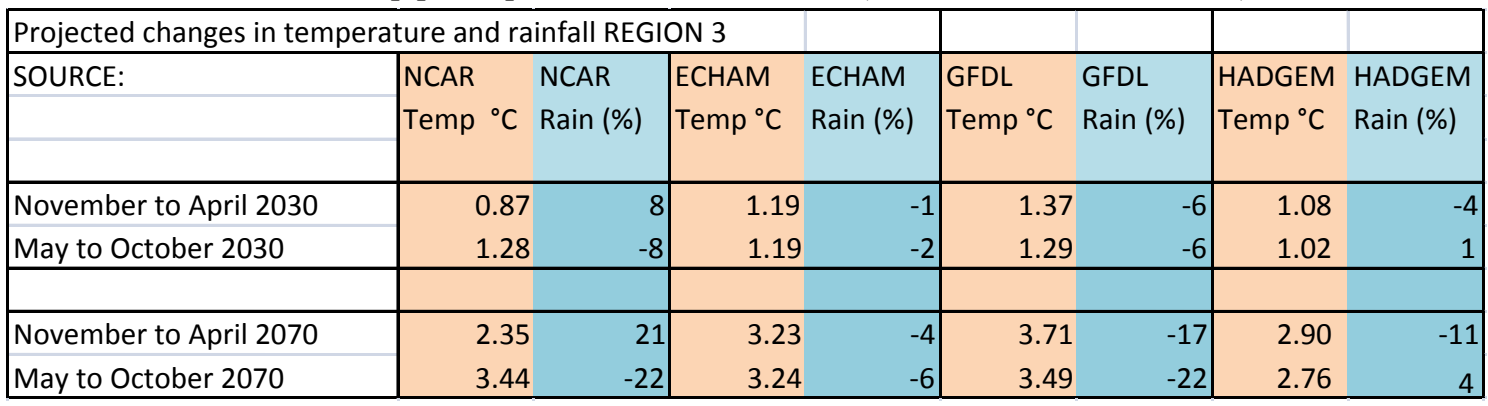

[NCAR = National Centre for Atmospheric Research; ECHAM = Max Planck Institute for Meteorology; GFDL $=$ Geophysical Fluid Dynamics Laboratory; HADGEM = Hadley Centre Global Environmental Model]

Table 2. Projected change scenarios for temperature and rainfall for Region 4 according to four of the best performing climate models available (derived from OzClim data and Kokic et al. 2010) as presented to workshop participants in the Kalgoorlie-Esperance region, WA (Source Loechel et al. 2010, 2013b)

\begin{tabular}{|c|c|c|c|c|c|c|c|c|}
\hline \multicolumn{9}{|c|}{ Projected changes in temperature and rainfall REGION 4} \\
\hline \multirow[t]{2}{*}{ SOURCE: } & NCAR & NCAR & ECHAM & ECHAM & GFDL & GFDL & HADGEM & HADGEM \\
\hline & Temp ${ }^{\circ} \mathrm{C}$ & Rain (\%) & Temp ${ }^{\circ} \mathrm{C}$ & Rain (\%) & Temp ${ }^{\circ} \mathrm{C}$ & Rain (\%) & Temp ${ }^{\circ} \mathrm{C}$ & Rain (\%) \\
\hline November to April 2030 & 1.09 & 4 & 1.09 & -1 & 1.16 & -5 & 0.93 & -4 \\
\hline May to October2030 & 1.14 & -6 & 1.09 & -6 & 1.02 & -5 & 0.76 & -5 \\
\hline November to April 2070 & 2.96 & 10 & 2.96 & -2 & 3.13 & -14 & 2.52 & -12 \\
\hline May to October 2070 & 3.07 & -16 & 2.46 & -15 & 2.76 & -47 & 2.07 & -13 \\
\hline
\end{tabular}

$[\mathrm{NCAR}=$ National Centre for Atmospheric Research; ECHAM = Max Planck Institute for Meteorology; GFDL = Geophysical Fluid Dynamics Laboratory; HADGEM = Hadley Centre Global Environmental Model]

Typically, during pre-workshop interviews and prior to presenting participants with the scenarios and analogues, discussion topics about climate change and adaptation requirements was largely around the apparent lack of knowledge or information, or the in ability to plan due to data uncertainties. Upon presenting the scenarios combined with the analogues in the workshop environment, we found that they provided a focus for discussion, as interaction across the workshop group became more dynamic and productive.

\section{DISCUSSION AND CONCLUSIONS}

Use of model projections, together with other supporting climate change information, to produce future climate scenarios in a workshop format has provided a user-friendly process for members of the mining value 
chain with diverse backgrounds to better understand modelling outputs. The process has proven to be a valuable aid for participants to explore practical implications of climate change, such as specific vulnerabilities and adaptation options for their organisation, over different timeframes. A further powerful advantage of the workshop-process has been that practitioners from different sectors have gained a deeper understanding of how climate change is likely to affect other sectors, and they were provided with the opportunity to discuss the likely flow-on effects between sectors with one another. Combined with analogues in the workshop environment, we found these tools improved understanding and encouraged discussion across the sectoral groups. The scenarios and peoples' understanding of them provide the basis for further organisational level assessments of climate change impacts and adaptation options.

\section{ACKNOWLEDGEMENTS}

The CSIRO Climate Adaptation Flagship, the Chamber of Minerals and Energy, Western Australia, Eastern Region, the Goldfields Environmental Management Group and the Goldfields Esperance Development Commission have provided support to facilitate research surveys and workshops. Whilst OzClim development as a web application was undertaken by CSIRO, we acknowledge the contributions of the Department of Climate Change, the Australian Bureau of Meteorology, the Program for Climate Model Diagnosis and Intercomparison and global warming data generated by Dr Sarah Raper using MAGICC.

\section{REFERENCES}

Australian Bureau of Statistics (ABS) (2012a). Year Book Australia, 2012. Cat. No. 1301.0. ABS, Canberra.

Australian Bureau of Statistics (ABS) (2012b). Labour Force, Australia, Detailed, Quarterly, Aug 2012. Cat. No. 6291.0.55.003. ABS, Canberra.

Adger, W. N., Arnell, N.W. and Tompkins, E.L. (2005). Successful adaptation to climate change across scales. Global Environmental Change-Human and Policy Dimensions 15:77-86.

Bureau of Meteorology (2013). Australian climate variability \& change - Trend maps, accessed online 3rd April 2013, $\quad$ http://www.bom.gov.au/climate/change/index.shtml\#tabs=Climate-changetracker\&tracker=trend-maps

Charles, S.P., Bari, M., Kitsios, A., and B.C. Bates, (2007). Effect of GCM bias on downscaled precipitation and runoff projections for the Serpentine Catchment, Western Australia. Int. J. Climatol., 27: 1673-1690.

Commonwealth Scientific and Industrial Research Organisation (CSIRO) and Bureau of Meteorology (2007). Climate change in Australia. Technical Report. www.climatechangeinaustralia.gov.au.

Connolley, W.M. and Bracegirdle, T.J. (2007). An Antarctic assessment of IPCC AR4 coupled models, Geophys. Res. Let., 34, L22505, doi:10.1029/2007GL031648.

Hall, J., Fu, G. and Lawry, J. (2007). Imprecise probabilities of climate change: aggregation of fuzzy scenarios and model uncertainties. Climatic Change 81:265-281

Hodgkinson, J.H., Littleboy, A., Howden, M., Moffat, K and Loechel, B. (2011). Climate adaptation in the Australian mining and exploration industries, Climate Adaptation Flagship Working paper \#5, CSIRO 32pp

Indian Ocean Climate Initiative (IOCI) (2012). Western Australia's Weather and Climate: a synthesis of Indian Ocean climate initiative Stage 3 Research. CSIRO and BoM, Australia, 119pp

IPCC (2007). Intergovernmental Panel on Climate Change Fourth Assessment Report, Climate Change, 2007 (AR4), http://www.ipcc.ch/publications_and_data/publications_and_data_reports.shtml

Kokic, P., Crimp, S. and Howden, M. (2010). Forecasting climate variables using a mixed-effect state-space model. Environmetrics 22(3): 409-419.

Loechel, B., Hodgkinson, J.H., Moffat, K., Crimp, S., Littleboy, A. and Howden, M. (2010). 'GoldfieldsEsperance Regional Mining Climate Vulnerability Workshop: Report on workshop outcomes'. CSIRO Report EP106666. Pullenvale: CSIRO Earth Sciences and Resource Engineering. 
Loechel, B., Hodgkinson, J.H. and Moffat, K. (2011). 'Pilbara Regional Mining Climate Change Adaptation Workshop: Report on workshop outcomes’. CSIRO Report EP118134. Pullenvale: CSIRO Earth Sciences and Resource Engineering.

Loechel, B., Hodgkinson, J.H. and Moffat, K. (2013a). Climate change adaptation in Australian mining communities: comparing mining company and local government views. Climatic Change. 119(2): 465-477.

Loechel, B., Hodgkinson, J.H., Prober, S. and Moffat, K. (2013b). Climate adaptation in regional mining value chains: A case-study of the Goldfields-Esperance Region, Western Australia. Prepared for the Chamber of Minerals and Energy, Eastern Region, WA and the Goldfields Environmental Management Group. CSIRO Earth Science and Resource Engineering Pullenvale, Australia. Report EP137045.

Maximo, C.C., McAvaney, B.J., Pitman, A.J., Perkins, S.E. (2007). Ranking the AR4 climate models over the Murray-Darling Basin using simulated maximum temperature, minimum temperature and precipitation. In. J. Climatol., in press. DOI: 10.1002/joc.1612.

Min, S-K., Legutke, S., Hense, A. and Kwon, W-T. (2005). Internal variability in a 1000-yr control simulation with the coupled climate model ECHO-G - II. El Niño Southern Oscillation and North Atlantic Oscillation. Tellus A, 57 (4), 622-640.

Nelson, R., Kokic, P., Crimp, S., Martin, P., Meinke, H., Howden, S.M., Devoil, P., Nidumolu, U. (2010). The vulnerability of Australian agriculture to climate variability and change: Part II-integrating impacts with adaptive capacity. Environmental Science \& Policy 13, 18-27.

Overland, J.E. and Wang, M. (2007). Future Climate of the North Pacific Ocean. Eos 88(16), 178-182.

Perkins, S.E., Pitman, A.J., Holbrook N.J. and McAveney, J. (2007). Evaluation of the AR4 climate models' simulated daily maximum temperature, minimum temperature and precipitation over Australia using probability density functions, J. Climate, 20, 4356-4376.

Queensland Resources Council (QRC) (2010). QRC submission: Queensland floods commission of inquiry 11March 2011. www.floodcommission.qld.gov.au/_data/assets/file/0018/6174/Queensland-ResourcesCouncil.pdf Accessed $6^{\text {th }}$ October 2013.

Reichler, T. and Kim, J. (2008). How Well Do Coupled Models Simulate Today's Climate? Bull. Amer. Met. Soc., 89(3), 303-311.

Smith, I.N and Chandler, E. (2009). Refining Rainfall projections for the Murray Darling Basin of SouthEast Australia: The Effect of Sampling Model Results Based on Performance. Climatic Change 97, 2, $197-$ 210.

Suppiah, R., Hennessy, K.J., Whetton, P.H., McInnes, K., Macadam, I., Bathols, J., Ricketts, J. and Page, C.M. (2007). Australian climate change projections derived from simulations performed for the IPCC 4th Assessment Report. Aust. Met. Mag. 56, 131-152.

Watterson, I. G. (2008). Calculation of probability density functions for temperature and precipitation change under global warming. J. Geophys. Res.,113, D12106, doi:10.1029/2007JD009254.

van Oldenborgh, G.J., Philip, Y.S. and Collins, M. (2005). El-Nino in a changing climate: a multi-model study. Ocean Science, 1, 81-95. 